\title{
RETHINKING DEVELOPMENT: GOING BEYOND THE POLITICAL AND ECONOMIC EQUATIONS OF THE VARIOUS HUMAN DIMENSIONS FOR SUSTAINABLE DEVELOPMENT IN AFRICA - PROBLEMS, PROSPECTS AND THE WAY FORWARD
}

\author{
J.W. FORJE \\ Department of Political Science, University of Yaounde 11-Soa, Cameroon.
}

\begin{abstract}
There is a serious need for African countries to rethink their development approach. Africa is only known in negative terms the world over. Something positive is also found in the continent contributing to human development and well-being. This paper takes a critical look at issues plaguing the continent's state of underdevelopment and argues that only the people can fashion their development path taking into cognisance the advantages of being a late-comer to the development process. These advantages can best be exploited with visionary leaders, responsive civil society and a cooperative international community working in tandem with progressive governments. Africa needs an enabling democratic environment, an environment where governments puts the interest of the poor first, pushing forward the virtues of democratic governance, partnership, participation and benefit-sharing among the key stakeholders: state-civil society-private sector and international community interface. It must at the same time avoid corrosive effects of corporate cronyism that promotes corruption and cynicism, which is at the heart of most governments in the continent. Bridges must be constructed between modernity and tradition, and between nature and human beings so that knowledge and technology are used to strengthen the positive well-being of the people. Therefore, the state, people and international community must come together to address the problems of overdevelopment, underdevelopment, environmental destruction and poverty. The conclusion is that Africa needs a developmental democratic state. A social contract or heightened covenant for comprehensive and positive actions built on common determination remains imperative. Proactive strategic policy measures are recommended as ways forward in a fast evolving global knowledge-based economy propelled by the dynamics of information and communication technology and genetic engineering. It is only through echoed common hope and vision that concerted efforts could bridge gulfs between development and underdevelopment, affluence and poverty, and nature's gift and human aspirations. A partnership of shared values must be constructed for the common good.
\end{abstract}

Keywords: benefit-sharing, democratic governance, development, empowerment, environment, human capacity building, inclusion, participation, poor, science and technology, shared values.

The world community has now an opportunity to focus on the development priorities of Africa better uses of human resources, sustainable development for agriculture and food production, preservation of the environment, international action to deal with debt, resource flows and commodities, the necessity for structural adjustment and internal reform.

George Birmingham [1]

Structural problems and root causes are part of the problem of 'state failure' but a key question for policy-makers is how well states deal with crisis.

Chesterman et al. [2]

\section{FACING THE REALITY BY RIGHTING THE WRONGS}

The environment of Africa is complex and sensitive to global change. Complex not only in nature but also in terms of the people and forces that impact on it locally and internationally. Complex because of the conspiracy of the ruling elites ganging up with external forces to exploit their people in the 
name of development and progress. Otherwise, why are the people poor in the midst of plenty? We need, therefore, to go beyond the political and economic equation to situate the African predicament. First, Africa is known in negative terms the world over: a continent of highly indebted poor countries; a continent of beggars; a continent endemic with HIV/AIDS, as if HIV/AIDS is of their making; a continent that exports its raw materials and imports what it does not produce. A continent where its youth are fleeing the borders into greener pastures at the cost of their lives. Unfortunately, Africa has no right to determine the prices of what it exports and imports. Who should be blamed? The departed colonial masters or the new custodians of power?

Fifty years is a short span in the life of a country. Fifty years ago, Africa attempted to shake off the shackles of colonialism - 'seek yeh the political kingdom' Kwame Nkrumah's slogan or dictum filled the radio waves of the continent, but failed to include the virtues of 'seek yeh the belly kingdom for all'. Independence as the political kingdom was attained and the belly kingdom for a selected a few. Fifty years after, the belly kingdom has eluded the vast majority of the population. Colonial rule has been replaced by ethnic rule, affluence for a few and abject poverty for the majority. Government is no longer by the people but by ethnic hegemonic forces and the 'men in khakis'.

Unfortunately, fifty years down the lane, should underdevelopment of the continent be attributed to colonialism or bad governance? For fifty years Africa has done nothing to prove that colonialism was wrong, and this remains the greatest crime ever committed against the people. This sets the tone, perception on global change and human dimension development in Africa. What are the problems, prospects and progress? Which way forward for the continent? All the indicators for poverty, underdevelopment, exploitation and marginalisation clearly show why African remains the least developed part of the world. At the same time, the continent goes on record as having many presidents who have been in office for more than fifteen years (e.g. Paul Biya of Cameroon (1982), Robert Mugabe of Zimbabwe (1980), Omar Bongo of Gabon (1967) and Hosni Mubarak of Egypt (1980)).

Since independence, social and economic development in Africa has seen some degree of acceleration for good and bad. The continent can no longer feed its increasing new mouths, in spite of advances in science and technology. Compared to other parts of the world, Africa has made no progress in the last two decades. It is the only continent that has witnessed continuous economic decline and falling living standards in the past two decades (Fig. 1). How can the lives of the poor in Africa most effectively and rapidly be improved? Interpreting Fig. 1 data is both bad news and good. The bad news is that Africa's position has been falling radically relative to other groups. The good news is that very high rates of growth have been proved possible in economies similar to Africa and has resulted in China progressing from being one of the poorest regions in the world to being nearly as rich as Southeast Asia in the space of twenty years. Why can Africa not follow the footprints of China? It should be noted that African countries like Nigeria, Ghana and Cameroon had a higher per capita income in the 1960s than some of the Asian Tigers. What went wrong? Why did these countries overtake African nations? It is often argued that growth in income is not nearly enough to solve the problem of poverty. It passes many of the poorest groups in society by and fails to recognise that the poorest cannot successfully participate in a world economy as they live in areas with little infrastructure, less access to education and no access to technology necessary for exporting. For the poorest, trade can be seen to be an irrelevance.

The continent is being forced into an emerging global world of knowledge-led economy lacking all the basic indicators for economic take-off. Corruption, poor governance and dictators or presidents for life syndrome remain the pride of the continent. Buy why? How prepared is the continent to embrace this wave of development? Would it lead to the construction of a new harmonious society or will the region slide further into the dark ages of societal inequity? The social, political and economic policies of African countries must be seriously reviewed with corruption and bad governance taking 


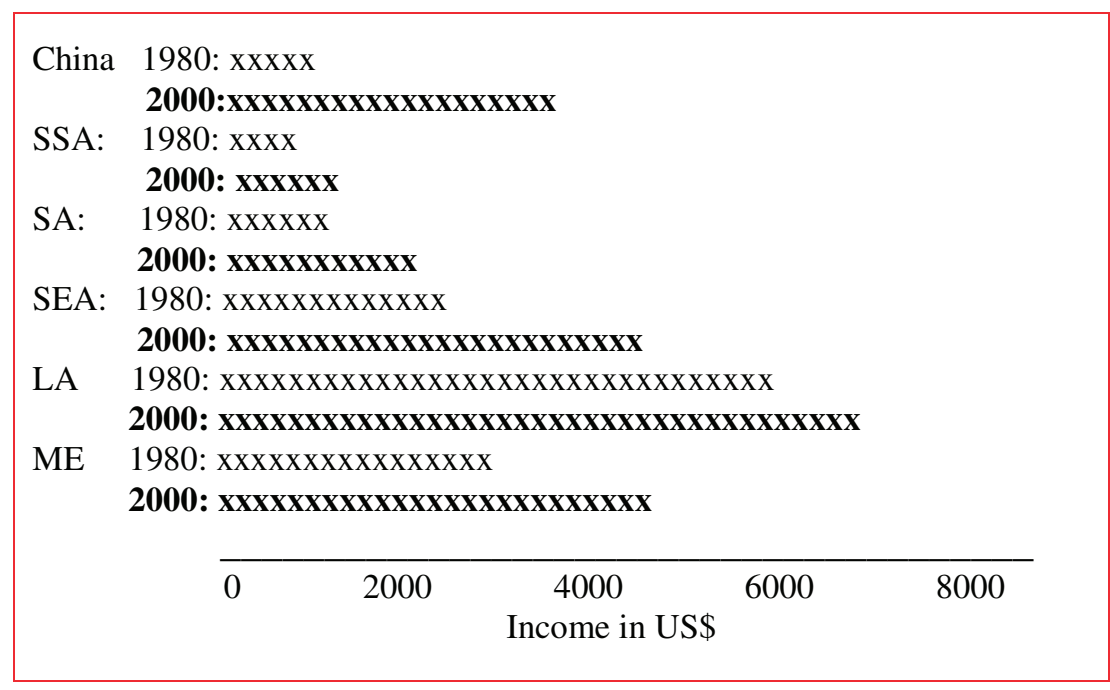

Figure 1: Changes in income per capita: 1980-2000. SSA, Sub-Saharan Africa; SA, South Asia; SEA, Southeast Asia; LA, Latin America; ME, Middle East. Source: GPRC Newsletter 4, November 2005, p. 1.

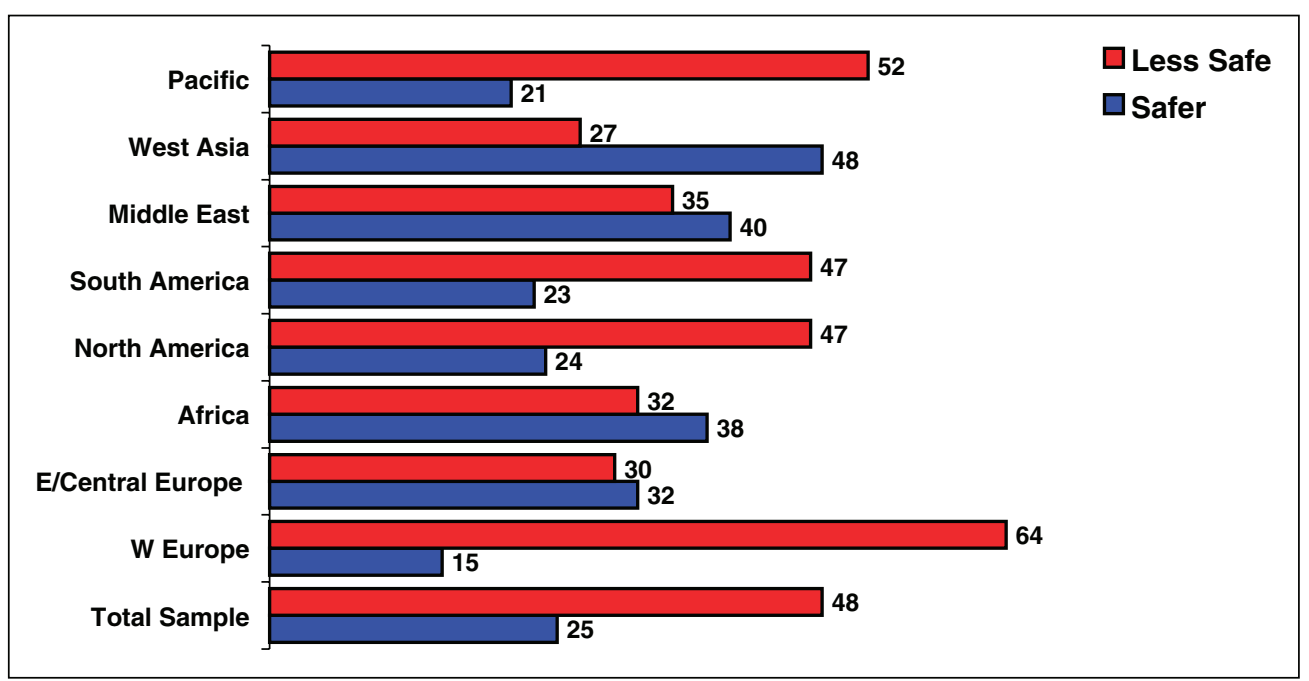

Figure 2: The next generation - a safer or less safe world? Source: Gallup International [3].

centre stage in the review process. This should be the common interest of African states if they are to march with the current development trends in the world. Is the world a safer place today than before? The results of a survey are illustrated in Fig. 2] indicating that the world is not a safe place at all, and Fig. 3, depicting the nations that are getting richer or poorer.

Among the findings of the survey, half of those interviewed (48\%) across the world think that the next generation will live in a less safe world. In Western Europe this figure rises to almost two-thirds 


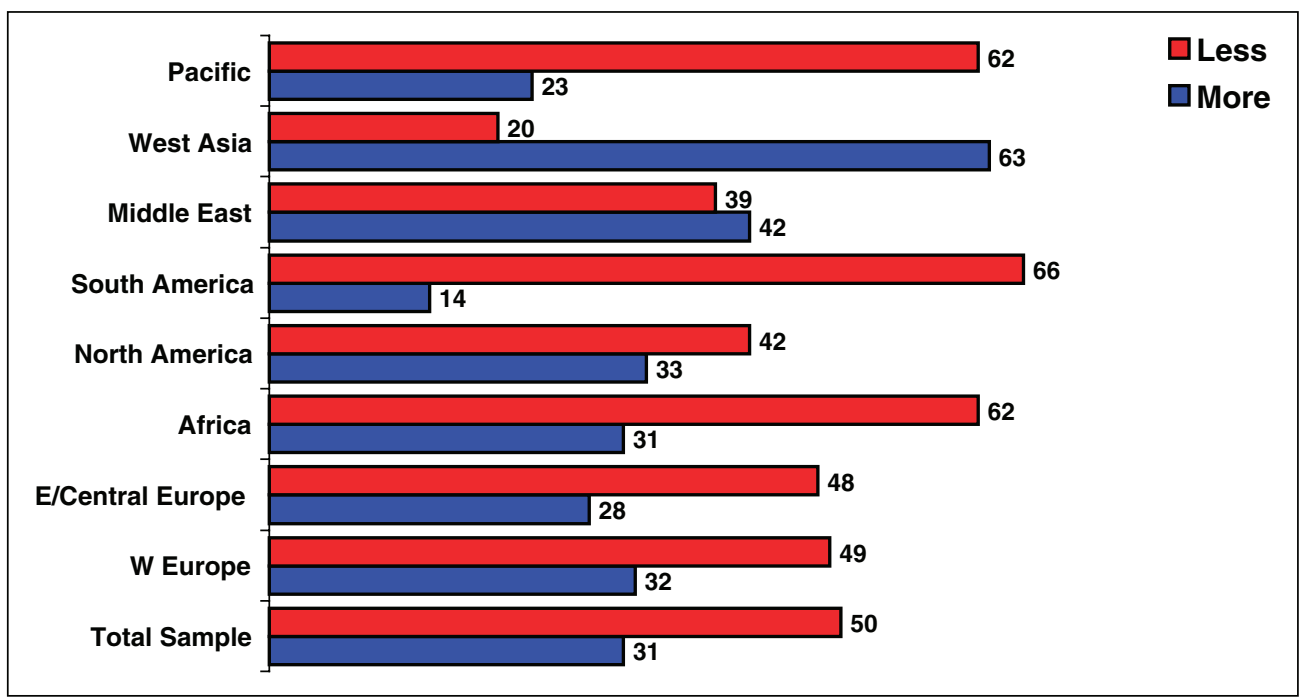

Figure 3: This country - more or less prosperous than ten years ago? Source: Gallup International [3].

(64\%). But in West Asia (Afghanistan, India and Pakistan), three countries with turbulent backgrounds, people are more optimistic about the next generation, and, here, half of those questioned feel that the world will be a safer place for them. The survey also found that people feel their country's economic position is worse now than it was ten years ago.

The theme of the World Economic Forum's Annual Meeting (21-25 January 2004) centred on 'Partnering for Security and Prosperity' and will see leaders from all sectors of society, business, politics, religion, NGOs and civil society discussing ways of improving the uncertain global climate. Speaking for the World Economic Forum, co-CEO Jose Mara Figueres said,

These findings paint a bleak picture indeed of how ordinary people see the future and their ability to affect events. Although there are signs of a changing environment both economically and in terms of security it seems this is still extremely fragile and the people at large have yet to be persuaded that things are changing. It is clear that both security and prosperity are core concerns for people across the world. What is also interesting is that without security those questioned felt that prosperity was impossible to attain and that the two - prosperity and security - must go hand in hand to make the world a safer and more peaceful place.

[Note: Interviewing was conducted in late November and December 2003, mostly prior to the capture of Saddam Hussein.]

\subsection{Summary of the main findings}

- Results from surveys consistently show that individuals feel they have little or no personal effect on the economic, political and social factors which affect daily life, expecting national and international actors to deliver the background stability required to look after and provide for their families [3]. 


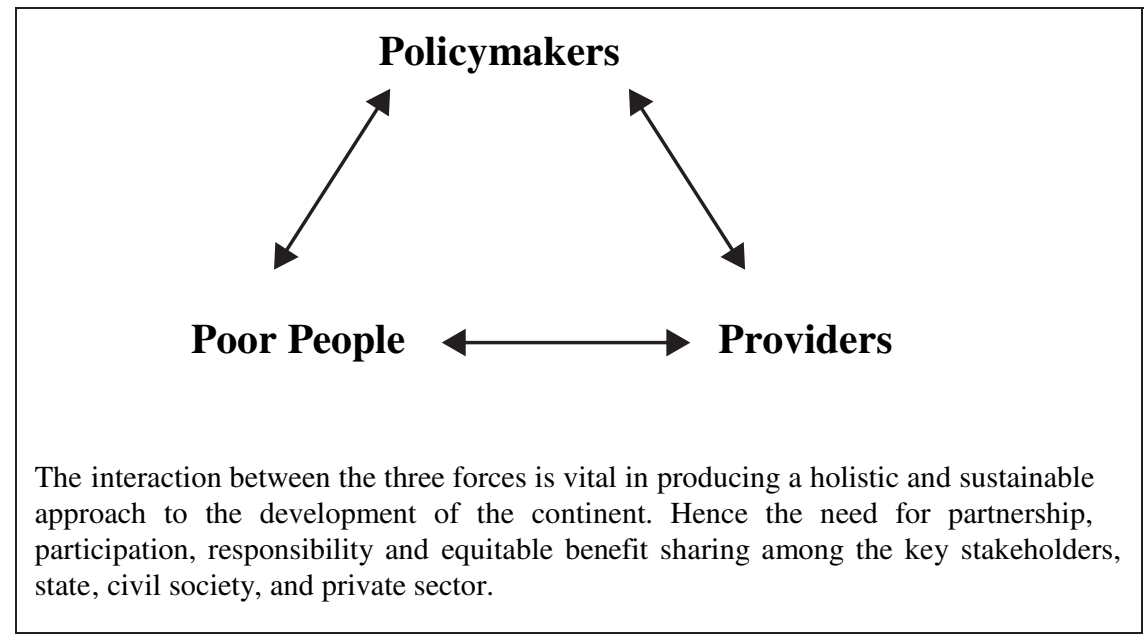

Figure 4: The accountability relationships approach.

- Uncertainty, lack of confidence and instability in one of these areas has an effect on all the other factors. For example, if people feel international and their national security is poor, they will also probably feel gloomy about their economic circumstances too, even if these are not objectively or directly linked [3].

Given that globalisation - the highest stage of scientific colonialism - rules the world, and based on the fact that Africa remains scientifically and technologically weak and underdeveloped, the question arises - can Africa meet the millennium development goals (MDGs) as the basis to kick start the quality of living conditions of its population to attain a minimum state of sustainable development without compromising the future and quality of the livelihood of future generations? The underlying element of this paper is simply one of 'soul searching', seeking solutions to pertinent issues that have eluded the people as human beings in this part of the world. In doing so, it builds on the accountability relationships approach (Fig. (4). The hallmark of this approach is for the decision tree to determine whether the state is pro-poor or clienteles.

What are the development priorities of the people? What visions do the political leadership have? What are the responses of the international community towards the aspirations and the needs of the people? Who should take the lead in deepening the governance process and quality services delivery in the region? Do the people want to develop - by what means and how? Global human dimension development must be approached from a holistic perspective. It is important for Africa and the world to find the right path of development that maintains harmony between humankind and nature, and to narrow the gap between poverty and affluence. There is a need for putting economic and political policy to test - by putting the poor first or crafting a 'human-faced' development approach.

\section{REDRAFTING THE DEVELOPMENT AGENDA}

Redrafting the development agenda calls for articulate political leadership and vision in relationship with concerted, integrated, comprehensive and harmonious social contract between (i) the state, (ii) civil society, (iii) private sector and (iv) the positive responses of the international community towards the aspirations and needs of the people, especially the currently marginalised and disadvantaged groups. African states need to expand, not contract, their public sector and dramatically improve 
its efficiency in delivery of quality public services that reaches all. In short, inequality and social and political divide must pave way for social justice and equality. Top on the list is strengthening partnership to achieve poverty alleviation and to eradicate the corruption syndrome.

Individual greed has contributed to excessive exploitation of natural resources, leading to conflicts over natural resources between people and nations. Today, natural disasters are becoming more frequent, more destructive and deadlier, and poor countries are being hit the hardest. The poor are pushed to living at the fringes of uninhabited areas lacking all the necessary basic amenities for good living. No wonder Africans are treated with contempt the world over as if they are not human beings. The leaders of African countries are to be blamed for the fate of their citizens. The quickening pace of change in the field of resources, and the coalition of international economies and politics, can well be illustrated by two recent snapshot views of the G8 Conference in Scotland (2005) and the WTO meeting in Hong Kong (2005). To this can be added the reluctance on the part of the industrial nations to create an enabling economic and political world order that incorporates the views of the non-industrial nations.

Given the plethora of issues involved, the paper advocates a triple heritage approach or collaboration between partnership, participation, responsibility and benefit-sharing among the key actors - (i) state, (ii) civil society (iii) private sector and (iv) the international community - in addressing issues of global environmental changes, globalisation, national/international security and sustainable development. What is significant is how to reduce vulnerability at the national, regional, continent and global levels. Of extreme importance is the need to enhance and harness indigenous knowledge in the development process. There is a need to tap into indigenous knowledge and to empower the people to be masters of their destiny. There is a need for the interface of these key actors because human modifications of land cover and land use has been a major driving force in earth system changes over the past centuries, and currently this change is being accelerated as a result of rapid economic development and the impacts of globalisation of some of the most complicated problems faced by policymakers around the world.

This is so because we have converted wrongly God's free gift to humankind into a moneymaking property for the few. We were given three things for free: Land $=\mathrm{L}$, Air $=\mathrm{A}$ and Water $=\mathrm{W}$, i.e. $\mathrm{L}+\mathrm{A}+\mathrm{W}=\mathrm{LAW}$. Unfortunately, today, we sell land and water. The only thing the poor have for free is air, which is being polluted. Because of greed in the name of profit maximisation, under the canopy of development and progress, polluting that free air implies taking away from the poor the only thing left for their existence. There is a need to share equitably what has been given freely by nature to humankind to ensure 'our common interest' [4], security and existence on planet earth. That is why it is necessary to make genuine efforts and realistic approaches to bridge the scale and epistemological gaps for land use decision-making through interdisciplinary study, participatory research and development, and science-policy interaction between the rich and the poor, the developing and the developed, and the North and the South, to rethink, reconstruct, reform and reconstitute a new national and global order to ensure a sustainable linkage between human needs, aspirations and ecosystems. There is a need to facilitate measures that address the scientific questions linking humans and ecosystems. A need to understand how various peoples and institutions adapt to effects and policies should be recognised. This also implies accelerating the pace of interdisciplinary cooperation across the blurring boundary between natural and social science.

There is a need for an interactive policy approach to policymaking and policy actions. The linear approach - Europe has the answers to the plight of the developing world - is long past its time and must be replaced by collective actions. We need policy approaches that will reduce poverty and limit the escalating wealth accumulations by the few who have gripped the world. We all want wealth. No one wants to be poor, to be born in poverty, live in poverty and be buried in poverty. With this in 
mind, why can development not be made to benefit all in society? The politics of resources scarcity has to be addressed anew so as to avoid conflicts within and between nations.

It is imperative for us to work jointly to eradicate or alleviate poverty and to stop pushing the vast majority of the poor to the fringes of extermination. In doing so, we are gradually pushing humankind out of planet earth. When nature takes its turn, it would not discriminate between the poor and the rich, though for now, it is always the poor who pay the price of earthquakes, hurricanes (Katrina, Rita) and other disasters. We need to open new frontiers to establish dialogue across disciplines, ethnic, racial and religious divides, and developed and developing or transitional societies to reach common grounds and to work for the common good of all. We need to construct new paradigms to bring the poor to the plus side of the development continuum and to ensure the maintenance of a sustainable ecosystem. A new development agenda is called for, an agenda that is holistic, comprehensive, integrated, human-oriented and sustainable ecosystem interlinked.

This is the time to act, because we are finding it hard to address one of the biggest threats of our time - the depletion of the ecosystem and the widening gap between the rich and the poor. The fact that global society is finding it so hard to appreciate the scale of the threat at hand, let alone do something about it, is of great historical significance. The rich or ruling elites in the developing polities have ganged up with the military-industrial complex of the west to bleed their own people to death. For how do we account for the billions of monies stacked in western financial institutions by African leaders, who beg and even bribe the west to be classified as highly indebted poor countries. Perhaps, one reason, as Juniper ([5], p. 12) points out, is that many people are divorced from nature that they have few ecological handles upon which they can anchor their experience.

The events of 26 December 2004 in Asia, Katrina and Rita in the USA, the recent earth quake in Pakistan (8 October 2005) and the floods in Guatemala should ring a bell: make our leaders understand the one bit of nature that people do not understand, namely the weather, and the impact of climate change which can be brought about by the hands of nature. Countries often pretend as if they are not responsible for causing climate change and the state of poverty. This attitude should change for countries, especially developing ones in the process of reclaiming development. Hence, for the poor, securing a political voice requires some degree of self-identity and vibrant consolidation of forces at all levels - power to the people. The climate is so fundamental and in popular terms so poorly understood that it seems to many most unlikely that people realistically have an impact on it in the first place. Given the urgency of the problem, and the evident failure of concerted and comprehensive efforts to curb emissions and eradicate poverty, people of good will, with the interest of the poor and the ecosystem at heart, must intensify their campaigns for evolving sustainable development patterns that meet the needs of present and future generations.

Hence, the need for building bridges across the great divides, for scientists to take their share of obligations and responsibilities. We all have a greater role to play in reminding us of our humanity. But what leaders in Africa in particular must do is to address the state of inhumanity to which they have and continue to subject their own people. This issue is taken up aptly by Salgado [6] (p. 29):

... humanity may have a special, often dominant, relationship with nature, but it is no less part of nature. Indeed, we cannot survive outside it. And yet accelerated urbanisation over the past century has distanced humanity from the very animal and plant sources of life itself. We are living in disharmony with the elements that comprise the universe, as if we too were not similarly formed, as if we were purely rational beings.... We assume grave risks when we distance ourselves from our natural roots, roots which in the past always made us feel part of the whole.

Never before in human history has the gap between those who labour and those who accumulate wealth without labour been greater. Never before has hate between cultures been so global. 
Never before has there been global convergence of three violent trends, the violence of wealth creation, the violence of 'culture wars' and the violence of militarised warfare ([7], p. 60), and if I may add, the technology of violence, the technology of mobility and the technology of destruction have attained the greatest height of human destruction. We need technology for human development and for peaceful coexistence and well-being. The international economic order makes each and very human being dependent on one another in the chains of production and the market. However, only a few have control over this dependency. The international system and the local systems in different countries are not entirely uniform, but a bunch of varying practices which do not meet the ideal of freedom and equality. Humanistic and ethical norms are not inbuilt in the present international system; indeed, often it is quite the contrary. This explains partly the sufferings of the poor and third world countries within the national and global context. Technology brings yet another controversial aspect to mutual dependency among humankind. Current well-being is based on technology, which is very much the same all over the world.

Incidentally, the technology of mobility, violence and destruction, and given the technology of knowledge, can be converted into technology for human development. Today the people of the developing world are faced with (i) the results of the coercive, undemocratic free trade treaties which are reduced to 'achievements' of information technology; and (ii) corporate control which is presented as collaborations and competition between individuals. We forget the impact of the WTO, the World Bank and IMF and multinational corporations. Consequently, globalisation is about technological inevitability and individual innovativeness, not a project of powerful corporations aided by powerful institutions and governments ([7], p. 61). Of course, it can be said that globalisation and information and communications technology have opened up the political space at least and dictators no longer have a monopoly to news censorship like before. As well as providing wellbeing, technology also determines the relationship between humankind and nature. In spite of more environmentally apt thinking and a growing awareness of the environmental issues, disposability will remain at the forefront of the relationship between modern technology and nature: produce, consume and cast aside as waste. The decisive choices to be made are ethical and demand ethical consciousness and the recognition of values as grounds for justified decision-making. The poor, especially in the developing polities, are calling for this ethical consciousness and justified decision-making. Here both the national and the global civil society remain the 'nucleus' of complex transformation for a just, ethical and caring decision-making system that ensures equality, liberty and freedom for all.

Therefore, ranges of climate-change-related impacts working in concert could lead to social instability, mass migrations of people, the rise of authoritarian regimes and international conflicts. Conflicts over natural resources are the order of the day. In West Africa, the Niger Delta region is the richest in terms of natural resource, yet it is the poorest in terms of development. Gabon and Nigeria started exporting oil before Norway, which was the poorest of the Scandinavian countries. Compare the life style of Norwegians to that of the Gabonese, Cameroonians or Nigerians. The conflict over the rich Bakassi peninsula between Cameroon and Nigeria when resolved will not only improve the living conditions of the people but will also accelerate the profit-making mechanisms of the oil producing companies and the ruling or governing authorities. But this depends on the kind of policies put in place by the authorities. Why is Africa poor in the midst of plenty? Something is missing somewhere, which must be adequately and seriously addressed. Importantly, global problems have to be dealt with in the global terms of objectives and cooperation, so also national and intranational problems. Solving global problems and meeting the challenges are tasks to be carried out both locally and in cooperation with the world community. This requires the availability of common resources and their coordinated use. Without this the problems remain unsolved, or scanty resources are directed to targets of secondary importance or are otherwise used ineffectively. 
We need a vibrant national and global civil society that in the end will forge positive actions to be taken in order to address the problems. These will come about as a result of growing public awareness that changes cultural values that help to shift politics, policy, law, and ultimately how we generate and consume energy, natural resources and how we judge good life. It is time to take stock and to act positively for the common good. It is time we break through the tyranny of power and money created by financial institutions and the political establishment, and recognise that a wealth of indigenous knowledge exists which should be brought into the political chess game to address the world's richest yet poorest continent. It is positive that there is increasing consensus about the need for long-term targets, but these will not be reached unless we begin the process of change - power to the people and equal opportunities for all. We need our people, our governments and the global community to act, and to act now, else our efforts will remain a kind of talk shop.

Thinking globally gives a broader scope for local actions and the coordination of politics, and facilitates more effective local solutions to conflicts. Hence, the target is the sustainable development of humankind and life with dignity to all. Every world citizen as well as every society is obliged to bear a share of this international responsibility by responding to the request to think globally and act locally for the common good. It is only from this common perspective that the issues of global human dimension can be solved and the planet earth can be made sustainable for present and generations yet to come. We should bear in mind that the world has only one nature for all people. Changes in the atmosphere, holes in the ozone layer, desertification, destruction of forests, the loss of biodiversity and pollution as well as accidents and disasters have their effects on nature as a whole, as well as on each human endeavour. Individual people as well as their societies come into closer and closer contact with each other, as communication systems are being developed and networks are connecting people in many new ways. We must all develop the power of ethical self-awareness and make life full of dignity for every human being. Therefore, a coordinated set of efforts at all human levels from global to local, collective to individual, material to social and spiritual remains the best way for a sustainable world environment. This should be the resolve of every nation and individual to enable us to claim the 21 st century and make the future better for those yet unborn.

\section{CONCLUSION}

One conclusion, above all, seems to us important to restate. The resource challenge confronting the international community is not the problem of halting consumption in the face of a fixed and diminished resource inventory. It has been argued, instead, that natural resources have a fluid and everchanging nature, that grounds exist for optimism (albeit qualified, political will) and that technology will solve the problems of exploration, extraction, substitution and environmental impact. However, the problem with the human development dimension in Africa is the absence of political will, foresight and sense of direction by those who wield political power. More often than not, a policy strategy of 'exclusion' and not 'inclusion' takes centre stage in running the state. This is backed by ethnic politics and the transformation of the state into a dynasty under the system of presidents for life syndrome. The idea of a top-bottom approach is detrimental to the realisation of sustainable development. Thus, preconceiving science and policy, in short good governance, in the preventive paradigm remains the best way forward. There is a need to clean the political and economic processes in order to improve the efficiency of the public sector in terms of resource use and minimising waste and misuse of resources. There is a need for an adequate level of investment in technological or social, political and economic change to prevent environmental harm. The preventive approach requires attention to be shifted from end-of-pipe to upstream decisions about the successful transformation of society and pushing forward R\&D strategies. Inevitably, this means finding criteria to determine decisions 
affecting environmental load and ensuring a sustainable form of development that will enhance the quality of livelihood for generations yet to come.

This paper argues that the relationship of knowledge to the world of policy is fundamentally different from dominant notions. Political will backed by scientific knowledge is generated in relation to social words, and its validity or invalidity depends not only on the degree of fit with nature but also on its correspondence with the social world. The subtle but deep indeterminacies which pervade the constitution of scientific knowledge have a large but ill-defined domain for which society has the responsibility to exercise human values and negotiate moral identities, but which has instead been unconditionally abandoned to the implicit (reductionist and instrumentalist) epistemic commitments of science ([8], p. 127). To confront fully the issue of values and policies will therefore require willingness to wrest open the scientific and political black boxes and consider their internal reconstruction for the sustainable development of the continent. In the graveyard of failed and abandoned projects in Africa, there are many tombstones that bear eloquent testimony to it. But if the development approach is human focused, this will not happen.

As Africa continues to be in crisis, to practice undemocratic governance systems, to swim in corruption, depletion of the ecosystem system will continue to be engraved on the tombstones of each country. There is a need for serious and urgent ethical change that (i) embodies a new national and world order with ethos as its basis; (ii) ensures every human being is treated in a humane way; (iii) ensures that the rules which protect life, embodying respect for life, respect for nature, justice in the economic and political order, tolerance and truthfulness, and equality, are entrenched in the structural-functional governance system of each country. Each country must ensure the preservation and conservation of its natural resources, economic balances and eco-balance for sustainable development. These are the hidden factors behind ensuring the issues of sustainable human dimension development.

In the end, it is believed that there must be an underlying political basis for constructive reciprocal relations between the proprietors of resources and the proprietors of markets and technology. But market forces will not alone be sufficient to bring about such harmony. The resource producers must be encouraged and enabled to feel that they are part of the world system. In the industrial complex of the old democracies, computers, despite the mythology, did not take important investment decisions to the contrary: the sense of confidence and 'rightness' plays a vital role. So also, in the transitional exporter polities, the feeling of having a genuine commitment to the rest of the world is necessary. In short, the politics of 'inclusion' must override the process and relationship between the different parts or structures of the world system. Perhaps, it is here that the plight of the worst placed countries may act as a catalyst which brings together all the other actors involved to ensure a sustainable human dimension development process. If a practical programme of positive actions to ameliorate the situation can be evolved cooperatively between all states (a role which given the chance to play the United Nations can embark upon) and with common sense allowed to prevail, then there will be solid ground for hope that constructive relations of global interdependence (collective inclusion) may yet be achieved. The underlying elements of the views presented can be best summarised under five headings as shown in Fig. 5. A practical programme of positive action to ease the declining or deteriorating situation of less developed societies can be evolved cooperatively between all other nations. Hence, it is imperative for African countries get 'seek yeh the political kingdom and belly kingdom for all' right, without which human dimension development will remain a talk shop with the risks of destroying the environment for present and future generations. The judicious use of resources must be the priority of all nations. It must be admitted that the problems and options facing Asian, African or South American policymakers will be as different as their size, populations, social system and geopolitical position. But generalisations are possible and many of the broader issues have been 
- To fight poverty and the unequal economic standing of the developing countries

- To secure that future generations will have the same possibilities of well-being which we have

- To stop the depletion of nature and the destruction of the environment

- Sustainable development is aimed to be social just and equal, ecologically and economically sustainable, politically and culturally free and innovative

- We are all-dependent on each other for our coexistence on planet earth and must ensure that mutually co-existence prevails on the basis of respect, justice and equality for every one

Figure 5: Suggested positive actions for the future.

thrown into sharp focus by the simultaneously shared experience of oil supply and price difficulties in the developing world since the events of October 1973. Those often hard hit are the poor. This is why the poor must be placed first in the development continuum agenda to attain sustainable development. There is a need to go further by recalling the views of Meadows et al. [9] who advocate 'Means, Actions For Sustainable Development', where:

- Sustainability = efficiency, sufficiency, justice, equity and community as high social values.

- Leaders are honest, respectful and more interested in doing their jobs than in keeping their jobs.

- Material sufficiency and security for all therefore becomes spontaneous by choice as well as by communal norms, low death rates, low birth rates and stable populations.

- Work that dignifies people instead of demeaning them. Some way of providing incentives for people to give their best to society.

- An economy that is a means, not an end, one that serves the welfare of the entire human community and the environment, rather than demanding that the community and the environment serve it.

- Efficient, renewable energy systems: efficient, cyclic materials systems, technical design that reduces pollution and waste to a minimum.

- Regenerative agriculture that builds soils, uses natural mechanisms to restore nutrients and control pests, and produces abundant, uncontaminated food.

- Preservation of ecosystems in their variety, with human cultures living in harmony with those ecosystems; therefore, high diversity of both nature and culture.

- Flexibility, innovation and intellectual challenge. Flourishing of science, a continuous enlargement of human knowledge.

- Greater understanding of whole systems as an essential part of each person's education.

- Decentralisation of economic power, political influence and scientific expertise.

- Political structures that permit a balance between short-term and long-term considerations. Some way of exerting political pressure on behalf of our grandchildren.

- High skills on the part of citizens and governments in the arts of non-violent conflict resolution.

- Print and broadcast media that reflect the world's diversity and at the same time bind together the cultures of the world with relevant, accurate, timely, unbiased and intelligent information, set into its historic and whole system context. 
- Reasons for living and for thinking well of oneself that do not require the accumulation of material things.

These are challenges and opportunities for countries to address as well as take advantage of to ensure a sustainable present and a brighter and better future for all We need the system of accounting needs developing, and, in particular, measures need to be found which would help the useful development of the economy, the political and governance system, the environment and its resources, and technology. We have to take people and nature into account to ensure our existence on planet earth. This should constitute the basic approach to defining an environmental national model of human dimension and global responsibility for sustainable development in the exploitation of the man-society-nature and development interface. Responsibility for the nation and the world presupposes responsibility for oneself. We should be collectively engaged and responsible for our own sake. The recognition of global responsibilities and the search for solutions to problems at the national level will not happen without the acceptance of new ways of thinking, and meaningful discussions at all societal levels to promote values, insight and visionary knowledge.

Africa is not an insignificant actor in international politics in terms of its political, economic and geo-strategic position that is constantly sought by the big powers. Poor leadership has taken away that significance to a large extent. Africa now plays second fiddle. But its influence on the international stage remains considerable, if national development remains stable, human focused and positive, and if international policies are realistic, credible and in that respect predictable. Africa must move from reactivity to proactivity. Friends of the continent should assist in developing equality, democracy, social justice and human rights, fighting underdevelopment and corruption with all its ills, and setting standards for their application through democratic governance under the canopy of 'inclusion', as well as respond positively to the quest of African countries in defining national and global ethics.

\section{WAYS FORWARD}

- An urgent need for democratic governance and for cultivating the culture of structural functionalism of democracy.

- Africa needs authentic AIDS (Alternative Internal Development Strategy), not social added problems (SAPs) or a SAP with a human face.

- Empowerment of women and other disadvantaged groups.

- Livelihood strategies, i.e. policy actions, must be people focused and improve the quality of life for all.

- Africa must learn to mobilise and make proper use of its domestic resources.

- A serious drastic paradigm shift or strategic development approach from top-bottom to bottom-up or people driven, i.e. putting the poor first, the rich or affluent last.

- Putting the sustainability of the world first to progress and development with a human face.

- Converting the weapons of the technology of human destruction into a technology of human development.

- Policies must be articulately geared at eradicating poverty and empowering women - human oriented.

- Policies for consolidating partnership with all key stakeholders and opening the political space.

- Improving political dialogue between those included and excluded with exclusion being eroded from the vocabulary of the development process of each country.

- Proper use of resources - human and natural - in the best interests of the people who should be the beneficiaries of these resources. In short, total renovation of the book-keeping process of 
the national economy and political system as well as integration of environmental and economic auditing in order to evaluate the real effects of decision-making more effectively.

\section{REFERENCES}

[1] Birmingham, G., Minister of State at the Department of Foreign Affairs, Dublin. The quote is from his Foreword to Ireland: Assistance to Developing Countries, Report for the Year 1985 (Dublin, Department of Foreign Affairs, undated), 1985.

[2] Chesterman, S., Ignatieff, M. \& Thakur, R., Making States Work. From State Failure to StateBuilding, United Nations University: Helsinki, Finland, 2004.

[3] Gallup International, Global Survey, 8 January 2004, South Africa; see http://www.Gallupinternational.com, http://www.voice-of-the-people.net/

[4] Commission for Africa, Our Common Interest, Report of the Commission for Africa, March 2005.

[5] Juniper, T., Time to Act: Climate Change. Resurgence, No. 232, September/October 2005.

[6] Salgado, S., Replenish the Earth. Resurgence, No. 232, September/October 2005; http:// arts.guardian.co.uk/salgado/story/0,,1301887,00.html, www.institutoterra.org

[7] Shiva, V., Flat Vision: A review of Thomas Friedman's The World is Flat. Resurgence, No. 232, September/October 2005.

[8] Wynne, B., Uncertainty and environmental learning: reconceiving science and policy in the preventive paradigm. Global Environmental Change: Human and Policy Dimensions, 2(2), pp. 111-127, 1992.

[9] Meadows, D.H., Meadows, D.L. \& Randers, J., The Limits to Growth, Universe Books: New York [A Report to the Club of Room], 1972; see Beyond the Limits of Growth. 